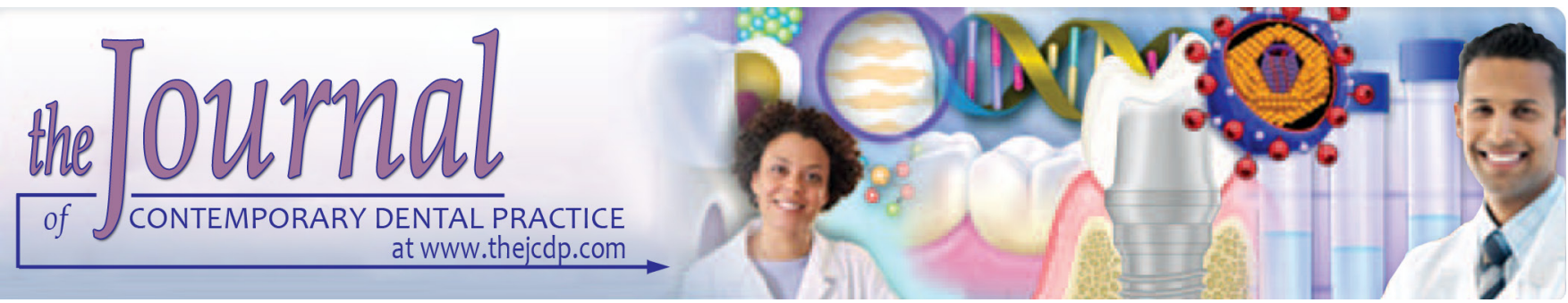

\title{
Alveolar Osteitis: Patient's Compliance with Post-extraction Instructions Following Permanent Teeth Extraction
}

\author{
${ }^{1}$ Mohammed K Alsaleh, ${ }^{1}$ Sarah S Alajlan, ${ }^{1}$ Nasser F Alateeq, ${ }^{1}$ Naif S Alamer, ${ }^{2}$ Freah Alshammary, ${ }^{3}$ Hazza A Alhobeira, \\ ${ }^{2}$ Saif Khan, ${ }^{2}$ Ammar A Siddiqui
}

\begin{abstract}
Aim: The study aims to evaluate the patients' compliance with post-extraction instructions to prevent the development of alveolar osteitis and keep the health of the socket. Alveolar osteitis "Dry socket" is considered one of the most common complications after extraction.
\end{abstract}

Materials and methods: Study was based on an observational cross-sectional design involving 201 subjects (individuals). The subjects were evaluated via a survey questionnaire and clinical examination after obtaining their verbal and written consent. The study questionnaire was divided into the following sections; section one records the demographic data about the subject while the second section focuses on self-assessment mainly regarding compliance with post-extraction instructions and pain.

Results: A total number of patients included in the study was $201,122(60.7 \%)$ male and $79(39.3 \%)$ female with an age of more than 18 years. No statistically significant association was reported between a medical condition and dry socket. Out of 201 patients came for clinical examination, 89 felt pain at the site of extraction at different period started from the day of extraction till the day of examination with various pain intensity. Females were the most to feel pain after tooth extraction with $78 \%$. Regarding prevalence, 14 (7\%) patients reported having dry socket and poor socket status. A statistically significant association of non-complying patients with the incidence of the dry socket was observed for a wide range of age (18 to 40 years)

Conclusion: The study showed a high degree of association between the incidence of dry socket cases for patients with

${ }^{1}$ Department of Preventive Dentistry, College of Dentistry, University of Ha'il, Ha'il, Kingdom of Saudi Arabia

${ }^{2}$ Department of Preventive Dentistry, College of Dentistry, University of Ha'il, Ha'il, Kingdom of Saudi Arabia

${ }^{3}$ Department of Restorative Dentistry, College of Dentistry, University of Ha'il, Ha'il, Kingdom of Saudi Arabia

Corresponding Author: Ammar A Siddiqui, Department of Preventive Dentistry, College of Dentistry, University of Ha'il, Ha'il, Kingdom of Saudi Arabia, e-mail: ammarqta2002@ hotmail.com poor compliance with post-extraction instruction. A strong relation was observed between the patients who felt pain and their gender (females)

Clinical significance: Based on the findings of the present study, we recommend the need to properly educate patients on the effect of compliance and the various complications and factors affecting the socket status after tooth extraction due to non-compliance.

Keywords: Alveolar Osteitis, Dry socket, Patient's compliance, post-extraction

How to cite this article: Alsaleh MK, Alajlan SS, Alateeq NF, Alamer NS, Alshammary F, Alhobeira HA, Khan S, Siddiqui AA. Alveolar Osteitis: Patient's Compliance with Post-extraction Instructions Following Permanent Teeth Extraction. J Contemp Dent Pract 2018;19(12):1518-1525.

Source of support: Nil

Conflict of interest: None

\section{INTRODUCTION}

Alveolar osteitis "dry socket" is considered one of the most common complications after extraction. Common symptoms include severe pain at the site of the extraction within 3 days, missing blood clot at the extraction site, bone visible at the extraction site, foul smell coming from the mouth, bad taste in the mouth. The occurrence of alveolar osteitis range from 0.5 to $5 \%$ of all extraction cases, But this range may increases up to $38 \%$ after the removal of impacted third molars (Fig. 1).

Most commonly after extraction of the mandibular third molar. Fibrinolysis of blood clot will lead to Alveolar osteitis. ${ }^{1}$ There are several factors which may increase the chance of developing alveolar osteitis. ${ }^{2}$ Such as low experience level of the operator, preoperative infection, sex, site of extraction, utilization of oral contraceptives, smoking, and use of local anesthetics with vasoconstrictor. The use of antibiotic, antifibrinolytic agents, mouthwashes, steroids, and intra-alveolar 


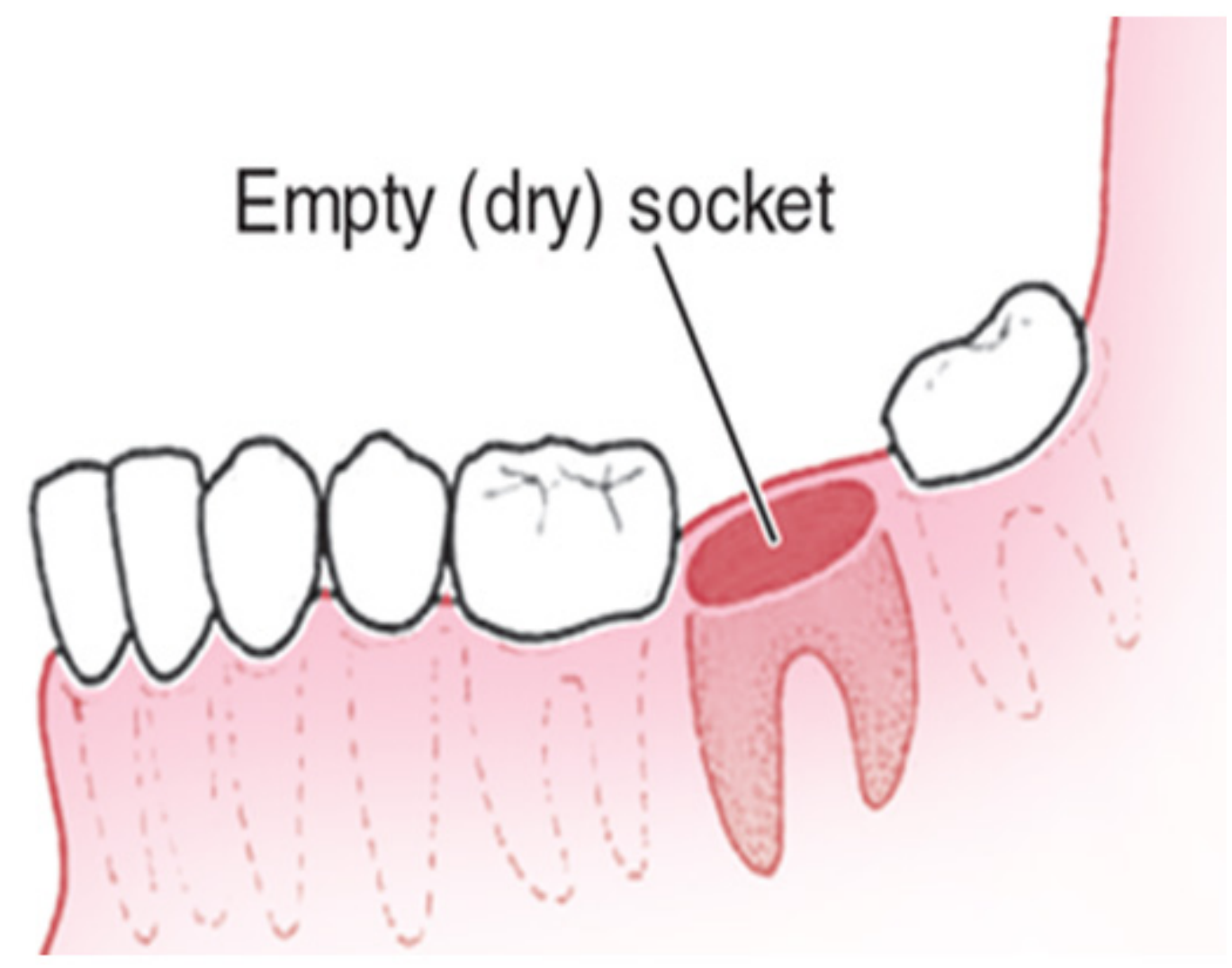

Fig. 1: Dry socket (https://www.kayawell.com)

medicaments decrease the chances of formation of alveolar osteitis. Patient reassurance, irrigation, and placement of intra-alveolar dressing are used to treat alveolar osteitis. $^{1}$

According to Sweet and Butler, 1979, the result of their study regarding the relationship between smoking and alveolar osteitis, there was a highly significant difference between two groups of patient (smokers and non-smokers). However, smokers were four times as great as non-smokers to develop dry socket. ${ }^{3}$ Another risk factor which is the use of oral contraceptive, where Garcia and Grana et al. proved that the use of oral contraceptive would increase the chance of developing alveolar osteitis. ${ }^{4}$ In 1968, Macgregor found that females were twice more than males to develop alveolar osteitis. ${ }^{5}$ Akinbami and Godspower, in their study, stated that lower teeth were at higher risk than uppers to develop alveolar osteitis, and posterior teeth more than anterior to develop alveolar osteitis, third molars, and retained roots were at higher chance to develop alveolar osteitis. ${ }^{6}$ Single tooth extraction is significantly higher to develop alveolar osteitis than multiple teeth extraction as reported by Nusair and Younis. ${ }^{7}$

Regarding the reduction of anarchy online (AO) incidence, warm saline mouthwash is similarly as compelling as chlorhexidine mouthwash, as prophylaxis against the counteractive action of alveolar osteitis after third molar surgery. ${ }^{8}$ Adebayo and Dairo 2005, reported that about warm saline mouthwash compliance is better among patients set on verbal instructions but generally, verbal and written instructions enhance compliance after oral surgical procedures. To inspire compliance, it is vital for postoperative instructions to be understandable for the patient including those not practically educated in the English language. The proper education which includes biting on gauze for 20 minutes until bleeding stops, swallow the saliva even if it is stained with blood, avoid hot drinks and hard food; only cold and soft, avoid smoking and avoid rinsing the mouth vigorously given to the patient postoperatively will enhance the satisfaction of the patient and reduce complications after the surgical procedure. ${ }^{9}$ On the other hand, the non-complying patient is defined as the patient who does not follow the doctor's instructions. This action may complicate the situation even worse. Many other factors may fail the treatment, but if the patient is said to be non-complying, that is considered to be the most critical one. A study made by Assiry in 2017, showed that $40 \%$ of patients were not complying with antibiotic prescription. ${ }^{10}$

Since there is no study regarding the patient's compliance with post-extraction instructions following extraction of permanent teeth in Ha'il region, this study will be conducted to enhance the compliance by keeping the health of the socket to prevent the development of alveolar osteitis. 


\section{MATERIALS AND METHODS}

It was an observational study with a cross-sectional design. The sample size of 201 patients (122 male, and 79 female) was evaluated after verbal and written consent. Each one of them underwent a single tooth extraction, the total no: of extractions considered in the study were 201. Duration of data collection was from February 18 till May 18. All the data collection was done at the dental clinics of the University of Hail. Local anesthesia (2\% lidocaine and 2\% Mepivacaine) was used for all procedures. The study was clearly explained to the patients, and they were guaranteed of keeping all the records confidential. No financial benefits were either given or received from the Patients. All teeth except impacted third molars were included in this study. A licensed OMF surgeon did a clinical examination. Ethical approval was obtained through the University of Hail ethical committee (H-2018-084). The study was performed at the dental clinics of Hail University, Hail, Kingdom of Saudi Arabia.

\section{Inclusion Criteria}

Patients criteria for inclusion were based on the American Society of Anesthesiologists (ASA) classification. Subjects classified as ASA I (Patients who are healthy otherwise) and ASA II (patients with the mild, controlled systemic disease with no limitation in function) were included in this study. These also included patients who had a permanent tooth extracted non-surgically in the past. All the cases mentioned above are included except impacted teeth since it needs surgical intervention which is not included in this study.

\section{Exclusion Criteria}

Exclusion criteria included those patients who required to be treated under general anesthesia, children under six years of age whom permanent dentition did not erupt yet, and any primary tooth exodontia.

\section{Post-extraction Instructions}

Patients were given post-extraction instructions verbally after the extraction which include biting on gauze for 20 minutes, until bleeding stops. Swallowing of saliva even if it is stained with blood. Avoid smoking for at least three days, Avoid hot drinks and food for the first day, avoid hard food for at least one day, eat or drink only cold and soft food for one day. Avoid vigorous rinsing for at least one day. Along with these, a paper full of formal written instructions were given to the patients. Instructions were translated in their regional (Arabic) language too, for the sake of understanding. Before they leave, patients were instructed to comply with instructions.
Patients with chronic systematic diseases were evaluated preoperatively, for example, diabetic patients wound healing is a concern and for cardiovascular patients, clotting time may vary depending upon their medication. Post-extraction instruction was stressed accordingly (primarily verbally). Avoid hot food and mouthwashes for a longer period as compared to what is prescribed in the general instructions. In general, the same instructions were more stressed for systemic diseases patients.

\section{Follow-up Examination}

One week after the procedure, patients were called for follow up visits to obtain information about the health status of the socket. Questionnaire and clinical examination were used as the study tool. The study questionnaire was having following sections; section one gathers the demographic data, medical history, and medications. Patients were divided according to their medical history into two groups; medically fit patients and patients with controlled systemic diseases. The second section focuses predominantly on compliance with post-extraction instructions and pain. Smoking habits, extraction site, instructions were given or not and for female oral contraceptive use was also enquired in the second section of the questionnaire. Patients were then divided according to their smoking habit into three groups non-smokers, $x$-smokers, and current smokers. The extracted teeth were classified according to their anatomical location into upper and lower.

\section{Classification of Compliance}

Patient compliance was distributed into three categories; compliant, who displayed an excellent compliant with the given instructions and socket was showing approximately satisfactory healing signs. Moderately compliant, who did not follow the instructions given precisely and ate from extraction side or smoked in the first 48 hours after exodontia or socket that contains debris. Non-compliant are the patients who did not obey the instructions, and at least two features of dry socket were observed in, that include throbbing radiating pain that developed 3 to 5 days after the extraction, loss of blood clot with a foul smell and unpleasant taste and jaw bone visible in the socket as a white area. Lastly, the compliance was assessed accordingly.

Clinical examination was done by a licensed OMF surgeon who was provided with the essential instruments to confirm the dry socket cases. Data was displayed as number and percentage, categorical data analysis using Pearson's chi-square test used to measure association, using the Statistical Package for the Social Sciences (SPSS) version 21 with $p$-value $\leq 0.05$ was considered significant. 


\section{RESULTS}

All of the 201 patients (122 males and 79 females, Table 1) appeared at the recall appointment date.

The patients were divided into five age groups: first, 6 to 18 years, second, 18 to 29 years, third, 30 to 39 years, fourth, 40 to 49 years, and fifth, 50 years and above.

The medical condition of the patients was obtained as follows: 181 of the patients were free of any systemic disease, 4 of them were having hypertension, six were diabetic, seven were suffering from sinusitis, and three were complaining of hypothyroidism (Graph 2). The reason for extraction were primarily caries and in some cases periodontal diseases and other specific reasons. Out of the 201 extractions performed, 97 (48.3\%) were in the upper jaw, while $104(51.7 \%)$ were in the lower jaw. 195(97\%) of the patients got the instruction after the extraction, and only $6(3 \%)$ did not receive any. These $(3 \%)$ were the cases which were well aware of the post-extraction instructions based on their previous extraction experience. Regarding smoking, 53 patients were smokers. Patients were instructed not to smoke

Table 1: Number and percentage of participants of study

\begin{tabular}{ll}
\hline Gender & $N(\%)$ \\
\hline Male & $122(60.7 \%)$ \\
Female & $79(39.3 \%)$ \\
\hline Total & $201(100 \%)$ \\
\hline
\end{tabular}

for the next three days some of them complied while some did not. Out of 53 smokers, 36 smoke on the day of extraction, while the 17 others did not (for the next 72 Hours). Out of 201 patients, $89(44.3 \%)$ felt pain at the extraction site, while $112(55.7 \%)$ had normal pain experienced after extraction. Out of 89 who felt pain 75 of them felt it immediately after extraction, and 10 of them felt it 24 hours after extraction, while 3 of them felt after 48 hours of extraction, and only one patient felt the pain after 72 hours post extraction. Painkillers if necessary were administered only on the first day. No antibiotics were prescribed given there is no previous and or sustaining infection. Fourteen $(7 \%)$ case of the 201 extraction cases developed dry socket; 147 (73.1\%) of the patient were complaint with the post-extraction instruction, $34(16.9 \%)$ were moderately complaint, and $20(10 \%)$ were non-complaint.

Out of the 14 patients, who got dry socket only $5(35.7 \%)$ of them were smokers. All the smokers who got dry socket did smoke on the first-day post extraction. There was no significant relationship between smokers and patients who got a dry socket $(p=0.128)$. Most of the dry cases observed (13 out of total 14) belong to the second and third age groups (18 to 29 and 30 to 39 years) however only 1 case fall in the fifth (50 or older) group. A significant association between age and patients who got dry socket was observed ( $\mathrm{p}=0.047$, Table 2$)$.

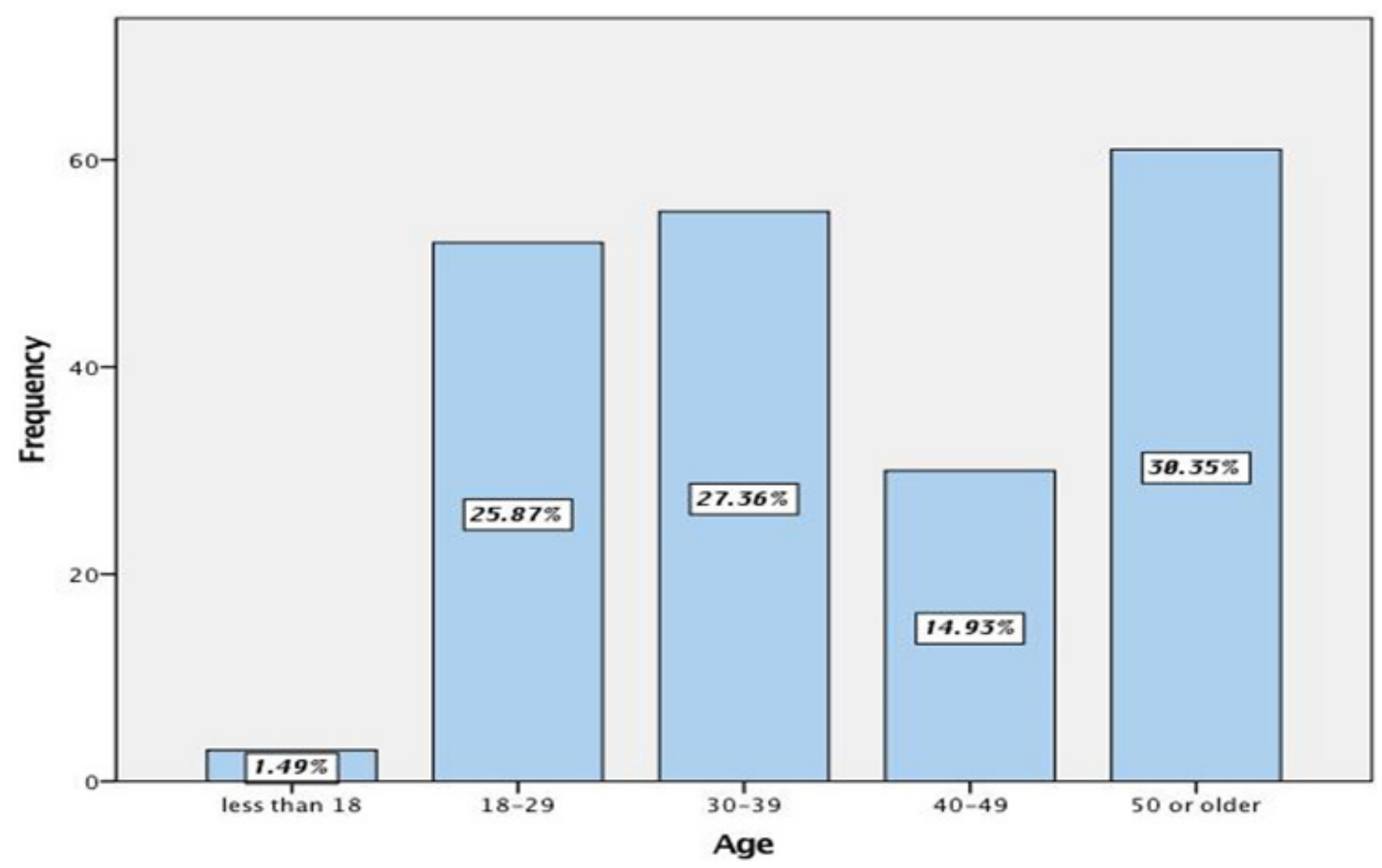

Graph 1: Participants age wise classification 


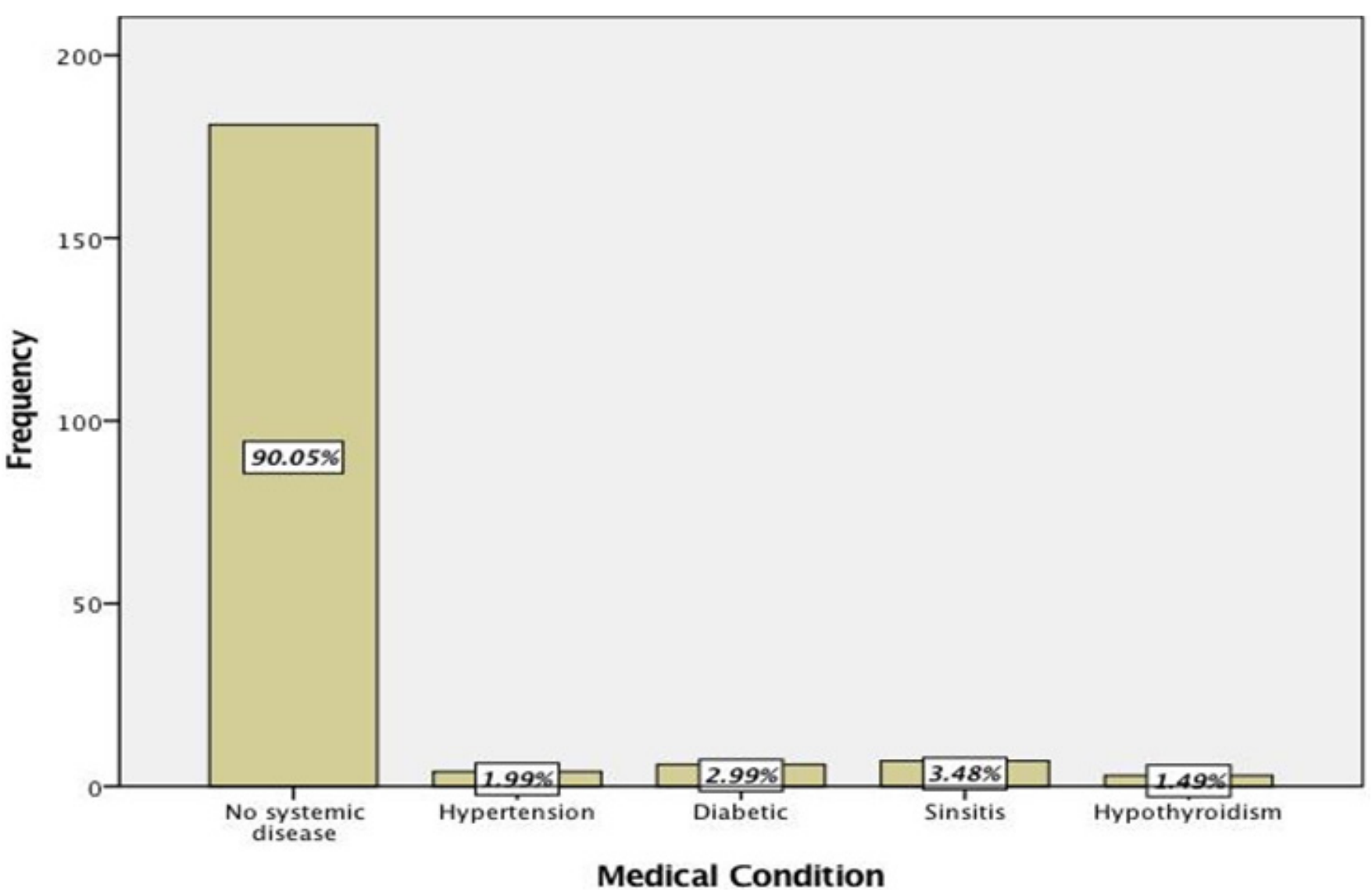

Graph 2: Participants medical condition wise classification

Table 2: Association of age with dry socket

\begin{tabular}{clllll}
\hline \multirow{2}{*}{ Age } & \multicolumn{3}{c}{ Socket status } & & \\
\cline { 2 - 4 } & & Dry socket & No complication & & T-value \\
\hline less than 18 & $6(11.5 \%)$ & $3(100.0 \%)$ & $5(1.5 \%)$ & \\
$18-29$ & $7(12.7 \%)$ & $46(88.5 \%)$ & $55(25.9 \%)$ & 0.047 \\
$30-39$ & $0(0 \%)$ & $48(87.3 \%)$ & $30(14.9 \%)$ & \\
$40-49$ & $1(1.6 \%)$ & $30(100 \%)$ & $61(30.3 \%)$ & \\
50 or older & $187(93 \%)$ & $60(98.4 \%)$ & $201(100 \%)$ \\
\hline Total & $14(7 \%)$ & $187(93 \%)$ & & \\
\hline
\end{tabular}

Non-complaint patients with post-extraction instructions are at much higher risk of developing dry socket than the other patients. We found that, out of 14 cases of dry socket, $8(57.1 \%)$ patients were non-complying with postextraction instructions. While only 2 (14.3\%) out of 14 were complying, and 4 (28.6\%) were moderately complying. A significant association was reported between the complying status of the patient and dry socket $(\mathrm{p}=0.000$, Table 3).

The lower teeth extractions are at more risk to develop dry socket than the upper teeth extractions. Out of 14 cases of dry socket, 11 (78.6\%) of them developed after extraction of teeth of the lower jaw, and only $3(21.4 \%)$ established after extraction of teeth of the upper jaw. There was a significant relationship between the site of extraction of the tooth (whether from the upper or the lower jaw) and dry socket ( $\mathrm{p}=0.037$, Table 4$)$.

\section{DISCUSSION}

Poor compliance of the patients is considered the main problem which causes post-operative complications. Compliance defined by Bunzel and Lederach-Hofmann as the cooperation of the patient with the doctor's instructions that result in the success of the treatment performed. ${ }^{11,12}$ Alveolar osteitis is one of the most common postextraction complications which leads to severe throbbing pain, bad breath, and unpleasant taste after three to five days of extraction with the jaw bone visible in the socket caused by fibrinolysis of the blood clot. Alveolar osteitis is highly related to poor compliance of the patient with postoperative instructions. The incidence of alveolar osteitis (according to Blum) is $\sim 3$ to $4 \%$ post extraction with higher incidence for the individuals in their 30s or 40 s. $^{13}$ The incidence of dry socket in the current study is higher following the simply closed dental extraction (7\%) 
Association of Alveolar Osteitis to Patient's Compliance

Table 3: Association of patient post teeth extraction instruction compliance with dry socket

\begin{tabular}{|c|c|c|c|c|}
\hline \multirow[b]{2}{*}{ Complaint status } & \multicolumn{2}{|c|}{ Socket status } & \multirow[b]{2}{*}{ Total } & \multirow[b]{2}{*}{$p$-value } \\
\hline & Dry socket & No complication & & \\
\hline Complaint & $2(1.4 \%)$ & $145(98.6 \%)$ & $147(73.1 \%)$ & \\
\hline Moderately complaint & $4(11.8 \%)$ & $30(88.2 \%)$ & $34(16.9 \%)$ & 0.000 \\
\hline Non-complaint & $8(40 \%)$ & $12(60 \%)$ & $20(10 \%)$ & \\
\hline Total & $14(7 \%)$ & $187(93 \%)$ & $201(100 \%)$ & \\
\hline
\end{tabular}

Table 4: Association of extraction teeth location with dry socket cases

\begin{tabular}{|c|c|c|c|c|}
\hline \multirow{2}{*}{$\begin{array}{l}\text { Where is the tooth/teeth that } \\
\text { you have extracted? }\end{array}$} & \multicolumn{2}{|c|}{ Socket status } & \multirow[b]{2}{*}{ Total } & \multirow[b]{2}{*}{$p$-value } \\
\hline & Dry socket & No complication & & \\
\hline Upper jaw & $3(3.1 \%)$ & $94(96.9 \%)$ & $97(48.3 \%)$ & \multirow{2}{*}{0.037} \\
\hline Lower jaw & $11(10.6 \%)$ & $93(89.4 \%)$ & $104(51.7 \%)$ & \\
\hline Total & $14(7 \%)$ & $187(93 \%)$ & $201(100 \%)$ & \\
\hline
\end{tabular}

and more frequent in the third and fourth decays of life similar to the study reported by Blum 2002 and relatively with Alhindi 2017.11,13,14

On the contrary, compliance of the patient with postextraction is profoundly affecting the wound healing postoperatively. This current study founds a significant association between non-compliance patient with postextraction instruction and alveolar osteitis. The patient may not relies on how vital the instructions are in taking care of the surgical site post-operatively, which make them ignore the instructions and put themselves at a higher risk to develop dry socket.

No statistically significant association was observed between the sex of the individual and the incidence of dry socket; however, it may be due to fewer female patients involved in the study This is inconsistent with most of the studies that found the female patient at higher risk to developing alveolar osteitis than male. ${ }^{15}$ Another study supports the concept of no gender susceptibility, and the current study suggested that no difference in male and female patients regarding the post-operative dry socket susceptibility. ${ }^{1}$

Oral contraceptive used by female patients (number of females on oral contraceptives: ${ }^{7}$ were found to have no role in causing post-operative dry socket as a result shown in the current study (Appendix I). By contrast, Garcia and Grana 2003 reported the increased cases of dry socket among female patients who are on contraceptive use three times more than others. The increased cases of dry socket explain the pharmacological activity of the drug due to its fibrinolysis activity which is one of the main factors that cause dry socket. ${ }^{16}$ The fewer number of ladies on contraceptive included may be the cause of the lacking result in the present study.

There was a statistical significance of the dry socket cases in mandible found in the current study where out of 14 cases reported to have a dry socket, 11 cases happened in the lower jaw. Several studies found that extraction performed in the lower jaw is at higher risk to develop alveolar osteitis than the upper jaw which is similar to the present study. Momeni and Shahnaseri 2011 conclude that mandibular cases were two times more than maxillary, especially in the lower third molar region. M, Khorasani 2007 reported that lower molar teeth are more prone to develop alveolar osteitis than the upper with a ratio of 2:1.15,17,18

The medically compromised patient involved in the study were ASA II and no statistical difference observed with the healthy individuals (ASA I). This was probably because of the place where the procedure was performed which was arranged merely in clinics lacking the hospital sitting ability. This was in contrast with the results of other studies. ${ }^{19-21}$ On the other hand, the finding of this study is similar to Nusair, Yonis, and Alhindi M. ${ }^{14,22}$ The previous literature mostly suggests that smokers are at higher risk to develop alveolar osteitis than other patients where they found a significant association between smoke and alveolar osteitis. ${ }^{1,22,23}$ Sweet suggests that smoking causes alveolar osteitis due to the foreign substance that could contaminate the surgical site and the suction and heat of cigarette. ${ }^{23}$ In this current study, there was no significant association between smoking and dry socket cases reported. It is consistent with the findings of Johnson and coworkers $1988 .^{24}$ The study has the following limitations: few female cases were considered, the study involved only few ASA II cases (only 20), Surgical removals were not considered and the study was performed in clinics, not hospitals.

\section{CONCLUSION}

Dry socket cases were found to be closely associated with the degree of patient compliance to post teeth extraction instructions. The study showed high dry socket cases in patients with poor compliance. The prevalence of dry socket cases reported in this study is slightly more 
Appendix 1

\begin{tabular}{lllll}
\hline *For females & \multicolumn{3}{c}{ Socket status } & \\
Are you taking the oral \\
\cline { 2 - 4 } contraceptive drug? & Dry socket & No complication & Total & p-value \\
\hline Yes & $0(0 \%)$ & $7(100 \%)$ & $7(8.9 \%)$ & 0.438 \\
No & $7(9.7 \%)$ & $65(90.3 \%)$ & $72(91.1 \%)$ & \\
\hline Total & $7(8.9 \%)$ & $72(91.1 \%)$ & $79(100 \%)$ & \\
\hline
\end{tabular}

(7\%) than what is reported earlier studies (5\%). Majority of alveolar osteitis cases were found in the mandibular posterior area especially, third molar region. It has been found that third and fourth decades of life are the most susceptible period for the disease to occur. There was no statistical association between patients having postoperative alveolar osteitis and their gender, smoking habit, and medical condition.

\section{CLINICAL SIGNIFICANCE}

Based on the findings of the present study, we recommend the need to properly educate patients on the effect of compliance and the various complications and factors affecting the socket status after tooth extraction. We suggest developing standard protocols for patient instruction and follow-up monitoring.

\section{REFERENCES}

1. Younis MHA, Ra'ed O. Dry Socket: Frequency, Clinical Picture, and Risk Factors in a Palestinian Dental Teaching Center. Open Dentistry Journal. 2011;5:7-12.

2. Bowe DC, Rogers S, Stassen LF. The management of dry socket/alveolar osteitis. Journal of the Irish Dental Association. 2011;57(6):305-310.

3. Sweet J, Butler D. The relationship of smoking to localized osteitis. J Oral Surg. 1979;37(10):732-735.

4. Garcia A, Grana P, Sampedro F, Diago M, Rey J. Does oral contraceptive use affect the incidence of complications after extraction of a mandibular third molar? British dental journal. 2003;194(8):453-455.

5. MacGregor A. Aetiology of dry socket: a clinical investigation. British Journal of Oral Surgery. 1968;6(1):49-58.

6. Akinbami BO, Godspower T. Dry Socket: Incidence, Clinical Features, and Predisposing Factors. International Journal of Dentistry. 2014;2014:796102.

7. Nusair Y, Younis M. Prevalence, clinical picture, and risk factors of dry socket in a Jordanian dental teaching center. J Contemp Dent Pract. 2007;8(3):53-63.

8. Osunde O, Anyanechi C, Bassey G. Prevention of alveolar osteitis after third molar surgery: Comparative study of the effect of warm saline and chlorhexidine mouth rinses. Nigerian Journal of Clinical Practice. 2017;20(4):470-473.

9. Adebayo E, Dairo M. Patients compliance with instructions after oral surgery in Nigeria. Journal of Community Medicine and Primary Health Care. 2005;17(1):38-44.
10. Assiry A, Ramalingam S, Amri A, Al-Mujaly A, Al-Elyani Y. Saudi Patients Compliance With the Antibiotic Course in Dentistry. Dentistry. 2017;7(431):2161-1122.1000431.

11. Bunzel B, Laederach-Hofmann K. Noncompliance in organ transplantation: a review. Wiener klinische Wochenschrift. 2000;112(10):423.

12. Bunzel B, Laederach-Hofmann K. Solid organ transplantation: are there predictors for posttransplant noncompliance? A literature overview. Transplantation. 2000;70(5):711.

13. Blum I. Contemporary views on dry socket (alveolar osteitis): a clinical appraisal of standardization, aetiopathogenesis and management: a critical review. International journal of oral and maxillofacial surgery. 2002;31(3):309.

14. AlHindi M. Dry Socket Following Teeth Extraction: Effect of Excessive Socket Saline Irrigation. J Oral Health Dent Sci. 2017;1:105.

15. Momeni H, Shahnaseri S, Hamzeheil Z. Evaluation of relative distribution and risk factors in patients with dry socket referring to Yazd dental clinics. Dental research journal. 2011;8(Suppl1):S84.

16. Garcia A, Grana P, Sampedro F, Diago M, Rey J. Does oral contraceptive use affect the incidence of complications after extraction of a mandibular third molar? British dental journal. 2003;194(8):453.

17. Heasman P, Jacobs D. A clinical investigation into the incidence of dry socket. The British journal of oral \& maxillofacial surgery. 1984;22(2):115.

18. Khorasani $\mathrm{m}$. The prevalence and risk factors of dry socket in dental surgery clients following tooth extraction at qazvin faculty of dentistry. 2006.

19. Birn H. Etiology and pathogenesis of fibrinolytic alveolitis ("dry socket"). International journal of oral surgery. 1973;2(5):211-263.

20. Torres-Lagares D, Serrera-Figallo M, Romero-Ruíz M, InfanteCossío P, García-Calderón M, Gutiérrez-Pérez J. Update on dry socket: a review of the literature. Medicina oral, patologia oral y cirugia bucal. 2005;10(1):81.

21. Lilly GE, Osbon DB, Rael EM, Samuels HS, Jones JC. Alveolar osteitis associated with mandibular third molar extractions. The Journal of the American Dental Association. 1974;88(4):802-806.

22. Nusair Y, Younis M. Prevalence, clinical picture, and risk factors of dry socket in a Jordanian dental teaching center. The journal of contemporary dental practice. 2007;8(3):53.

23. Sweet J, Butler D. The relationship of smoking to localized osteitis. Journal of oral surgery (American Dental Association: 1965). 1979;37(10):732-735.

24. Johnson WS, Blanton EE. An evaluation of 9-aminoacridine/ Gelfoam to reduce dry socket formation. Oral Surgery, Oral Medicine, Oral Pathology. 1988;66(2):167-170. 


\section{KINGDOM OF SAUDI ARABIA \\ MINISTRY OF EDUCATION UNIVERSTY OF HAIL Collage of Dentistry}

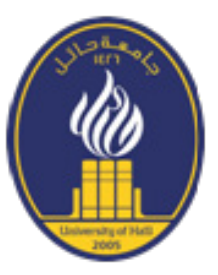

1. Name (optional)

3. Age : $\square$ less than 18 .

$\square$ 18-29.

30-39.

2. Gender: $\bigcirc$ Male $\bigcirc$ Female

4. Medical History:

$\square$ 40-49. $\square 50$ or older

$\square \quad$ No systemic disease.

$\square$ Hypertension.

$\square \quad$ Diabetic.

$\square \quad$ Other.

5. Under any medication?
$\square \quad$ No medication.
$\square \quad$ Antihypertensive.
口 Anti-diabetic.
$\square \quad$ Other

${ }^{*}$ check the right answer please :-

8. Where is the tooth/teeth that you have extracted ?
$\square \quad$ Upper.
$\square \quad$ Lower.

9. Did the doctor give you instruction after the extraction ?
r Yes.
$\square \quad$ No.

10. Do you smoke?
Yes.
№.

11. If yes, did you smoke at the day of extraction?
$\square \quad$ Yes.
$\square \quad$ No.

12. *For females, are you taking oral contraceptive drug ?
$\square \quad$ Yes.
$\square \quad$ No.

13. Did you feel pain at the site of extraction?
$\square \quad$ Yes.
$\square \quad$ No.

14. If yes, when did you feel it?
口 Immediately after extraction.
24 hours after extraction.
48 hours after extraction.
72 hours after extraction.
$\square \quad$ Other, specify.

${ }^{*}$ For recall,

14. Patient compliance with post-extraction instructions :
$\checkmark$ Compliant.
$\square \quad$ Moderately compliant.
$\square \quad$ Non-compliant.

15. Socket status :
Dry socket.
$\square \quad$ No complications. 